\title{
Evaluation of Bone Healing on Sandblasted and Acid Etched Implants Coated with Nanocrystalline Hydroxyapatite: An In Vivo Study in Rabbit Femur
}

\author{
Lory Melin Svanborg, ${ }^{1,2}$ Luiz Meirelles, ${ }^{2}$ Victoria Franke Stenport, ${ }^{3}$ Per Kjellin, ${ }^{4}$ \\ Fredrik Currie, ${ }^{4}$ Martin Andersson, ${ }^{5}$ and Ann Wennerberg ${ }^{1,2}$ \\ ${ }^{1}$ Department of Prosthodontics, Faculty of Odontology, Malmö University, 20506 Malmö, Sweden \\ ${ }^{2}$ Department of Biomaterials/Handicap Research, Institute of Clinical Sciences, Sahlgrenska Academy, Gothenburg University, \\ 40530 Göteborg, Sweden \\ ${ }^{3}$ Department of Prosthodontics/Dental Material Science, Institute of Odontology, Sahlgrenska Academy, Gothenburg University, \\ 40530 Göteborg, Sweden \\ ${ }^{4}$ Promimic AB, 41292 Göteborg, Sweden \\ ${ }^{5}$ Department of Chemical and Biological Engineering, Applied Surface Chemistry, Chalmers University of Technology, \\ 41296 Göteborg, Sweden
}

Correspondence should be addressed to Lory Melin Svanborg; lory.svanborg@mah.se

Received 30 July 2013; Revised 24 September 2013; Accepted 17 October 2013; Published 2 March 2014

Academic Editor: Ryo Jimbo

Copyright (C) 2014 Lory Melin Svanborg et al. This is an open access article distributed under the Creative Commons Attribution License, which permits unrestricted use, distribution, and reproduction in any medium, provided the original work is properly cited.

This study aimed at investigating if a coating of hydroxyapatite nanocrystals would enhance bone healing over time in trabecular bone. Sandblasted and acid etched titanium implants with and without a submicron thick coat of hydroxyapatite nanocrystals (nano-HA) were implanted in rabbit femur with healing times of 2, 4, and 9 weeks. Removal torque analyses and histological evaluations were performed. The torque analysis did not show any significant differences between the implants at any healing time. The control implant showed a tendency of more newly formed bone after 4 weeks of healing and significantly higher bone area values after 9 weeks of healing. According to the results from this present study, both control and nano-HA surfaces were biocompatible and osteoconductive. A submicron thick coating of hydroxyapatite nanocrystals deposited onto blasted and acid etched screw shaped titanium implants did not enhance bone healing, as compared to blasted and etched control implants when placed in trabecular bone.

\section{Introduction}

Dental implant treatment is today a very reliable method that provides good clinical results with success rates over $90 \%$. Generally, lower implant survival rates have been reported in the maxilla than in the mandible, due to the difference in bone structure [1-4]. However, the optimal implant surface is yet to be developed. The current aim is to develop surfaces resulting in improved success rates in implant sites with poor bone quality and quantity. Several factors have previously been identified to be of particular importance to achieve successful osseointegration. Such factors include the surface topography, at least on a micrometer level of resolution [5]. A surface with an average surface roughness $\left(S_{a}\right)$ of approximately $1.5 \mu \mathrm{m}$ has been shown to give a stronger bone response compared to smoother $\left(S_{a}<1.0 \mu \mathrm{m}\right)$ and rougher surfaces $\left(S_{a}>2 \mu \mathrm{m}\right)$ [6]. However, research is today often aimed at evaluating the importance of nanometer-sized structures, especially in the early bone healing phase. Several in vitro studies have shown an increased cell response to surfaces with applied nanostructures compared to surfaces without such structures [7-15]. During the last few years in vivo studies have also shown promising results on bone healing to different nanostructured titanium (Ti) implant 
surfaces [16-18]. Further, some human studies have provided evidence of improved bone healing to $\mathrm{Ti}$ implants with applied nanostructures [19]. Despite this, the knowledge of the importance of nanostructures in bone healing is still limited and the significance of nanoirregularities in the clinical treatment of patients is currently unknown. According to earlier experimental and clinical studies of implants with micrometer level irregularities, plasma-sprayed hydroxyapatite (HA) coated implants have a stronger initial bone response compared to conventional titanium implants. However, long-term clinical results of the same implants have been poor. This may be explained by the plasma spraying method resulting in coats of a thickness of $50-200 \mu \mathrm{m}$ and with poor adhesion to the underlying metal $[20,21]$. However, it was never investigated whether the initially positive bone response to the plasma-sprayed HA coats was due to an alleged superior biocompatibility of HA, to possible alterations in surface topography, or to a greater press fit of the thicker HA-coated implants when placed in the same sized sites as the controls. To improve the coating and minimize potential problems of coat loosening, thinner HA coats have been developed. A previous study by Svanborg et al. [22] did not support the importance of a nanocrystalline HA coat deposited on sandblasted and acid etched dental implants when placed in cortical bone. Rabbit tibia is suggested to simulate the bone of the human mandible and rabbit femur that of the human maxilla [6]. It may be that nanostructures are of benefit in trabecular bone, which do not provide satisfactory initial stability in contrast to the cortical bone site investigated in our previous study [22]. The use of blasted and acid etched dental implants has shown good clinical results [23] and it would be of interest to investigate if an added coat of nanocrystalline HA further improves the early bone healing in trabecular bone. The aim of this study was to investigate if a submicron thick coating of hydroxyapatite nanocrystals would enhance the bone healing over time, when deposited on sandblasted and acid etched screw shaped implants and placed in trabecular bone.

\section{Material and Methods}

2.1. Implants. The implants used in this study were threaded, sandblasted and acid etched titanium screws (grade 4) having a diameter of $3.5 \mathrm{~mm}$ and a length of $8.5 \mathrm{~mm}$ (custom made). A HA coating was applied on the test implants using a modification of the technique previously described by Kjellin and Andersson, 2006 [24]. This method creates an aqueous dispersion of nanosized HA crystals, sized $\sim 5 \mathrm{~nm}$, which are coated with amino acids. The coating of amino acids presents a positive crystal charge, which makes the crystals adhere to negatively charged surfaces, such as a titanium surface. The dispersion was applied onto the implant, and the implant was rotated in a spin-coating apparatus at $3000 \mathrm{rpm}$. The coated implant was dried in air, and a heat treatment at $550^{\circ} \mathrm{C}$ for 5 minutes in an oxygen rich atmosphere was done in order to sinter the HA particles onto the titanium surface and to remove the amino acids. With this method, the thickness of the resulting HA layer could be varied depending on the rotating speed. The rotating speed was set in such a way that the resulting HA layer was less than a micrometer thick, which was estimated using a Leo Ultra 55 FEG high resolution scanning electron microscope (SEM) (Carl Zeiss SMT Inc., North America). Powder X-ray diffraction (XRD) was used to determine the presence of crystalline HA structures. XRD was performed using a Bruker XRD D8 Advance (Bruker AXS, Karlsruhe, Germany) and monochromatic $\mathrm{Cu}$ radiation. Sandblasted and acid etched titanium implants were used as control.

2.2. Implant Surface Analysis. The implants were examined using SEM, operating at an acceleration voltage of $10 \mathrm{kV}$ (Leo Ultra 55 FEG high resolution SEM, Carl Zeiss SMT Inc.). The magnification used was $\times 40000$ and the micrographs were recorded at randomly chosen areas of the implants. The surface roughness was examined using a white light interferometer (MicroXAM, Phaseshift, Arizona, USA) which is as a highly suitable technique to evaluate threaded implant surfaces [25]. An $\times 50$ objective and a zoom factor of 0.62 were used in this study. The measured area had a size of 264 $\times 200 \mu \mathrm{m}$ and the vertical measuring range was $100 \mu \mathrm{m}$. The maximal resolution of the technique is $0.3 \mu \mathrm{m}$ horizontally and $0.05 \mathrm{~nm}$ vertically. To be able to describe the surface topography, the roughness, the waviness and shape must be taken into consideration. The standard filter used to separate micrometer roughness from waviness, and shape is a highpass Gaussian filter. A filter size of $50 \times 50 \mu \mathrm{m}$ has been used for threaded implants. To evaluate the height deviation at the nanometer level a filter size of $1 \times 1 \mu \mathrm{m}$ was used in this study, as suggested by Svanborg et al. [26]. Surfascan software (Somicronic Instrument, Lyon, France) was used to do the filtration and evaluation. This equipment provides images and numerical descriptions of the surface topography. SPIP (Image Metrology, Denmark) was used to do 3Dillustrations of the surfaces. Three implants from each group were examined. Three valleys on each implant were measured and evaluated.

For numerical description of the surface topography, four parameters were used:

$$
\begin{aligned}
& S_{a}=\text { the arithmetic mean of the roughness area from } \\
& \text { the mean plane; } \\
& S_{\mathrm{ds}}=\text { density of summits, that is, number of peaks per } \\
& \text { area unit; } \\
& S_{\mathrm{dr}}=\text { the ratio between the developed surface area and } \\
& \text { a flat reference area; } \\
& S_{\mathrm{ci}}=\text { core fluid retention index. }
\end{aligned}
$$

The parameters used represent one amplitude $\left(S_{a}\right)$, one spatial $\left(S_{\mathrm{ds}}\right)$, one hybrid $\left(S_{\mathrm{dr}}\right)$, and one functional $\left(S_{\mathrm{ci}}\right)$ value. The functional parameter, core fluid retention index $\left(S_{\mathrm{ci}}\right)$, is related to the bone biological ranking based on earlier studies on micrometer level. A low value may be related to a positive biological outcome of bone anchored implants [27]. Mathematical formulas for the parameters can be found in the literature [28].

X-ray photoelectron spectroscopy (XPS) was used for characterisation of the surface chemical compositions. XPS 
TABLE 1: Results from the interferometer characterization. The numbers represent the mean value of each parameter (the standard deviation is presented within parenthesis).

\begin{tabular}{lcccccccc}
\hline & \multicolumn{3}{c}{ Gauss filter $50 \times 50 \mu \mathrm{m}$} & \multicolumn{3}{c}{ Gauss filter $1 \times 1 \mu \mathrm{m}$} \\
& $S_{a}(\mu \mathrm{m})$ & $S_{\mathrm{ds}}\left(/ \mathrm{mm}^{2}\right)$ & $S_{\mathrm{dr}}(\%)$ & $S_{\mathrm{ci}}$ & $S_{a}(\mathrm{~nm})$ & \multicolumn{2}{c}{$S_{\mathrm{ds}}\left(/ \mathrm{mm}^{2}\right)$} & $S_{\mathrm{dr}}(\%)$ \\
\hline \multirow{2}{*}{ Control } & 1.08 & 1184807 & 142.5 & 1.21 & 114 & 2055650 & 74.9 & 0.95 \\
& $(0.41)$ & $(244569)$ & $(73.0)$ & $(0.18)$ & $(11.1)$ & $(106081)$ & $(13.4)$ & $(0.12)$ \\
\multirow{2}{*}{ Nano-HA } & 0.93 & 1259841 & 146.5 & 1.12 & 119 & 2132025 & 83.9 & 0.84 \\
& $(0.25)$ & $(143100)$ & $(46.0)$ & $(0.25)$ & $(6.9)$ & $(78489)$ & $(8.9)$ & $(0.04)$ \\
\hline
\end{tabular}

$S_{a}$ : the arithmetic mean of the roughness area from the mean plane; $S_{\mathrm{ds}}$ : density of summits, that is, number of peaks per area unit; $S_{\mathrm{dr}}$ : the ratio between the developed surface area and a flat reference area; $S_{\mathrm{ci}}$ : core fluid retention index.

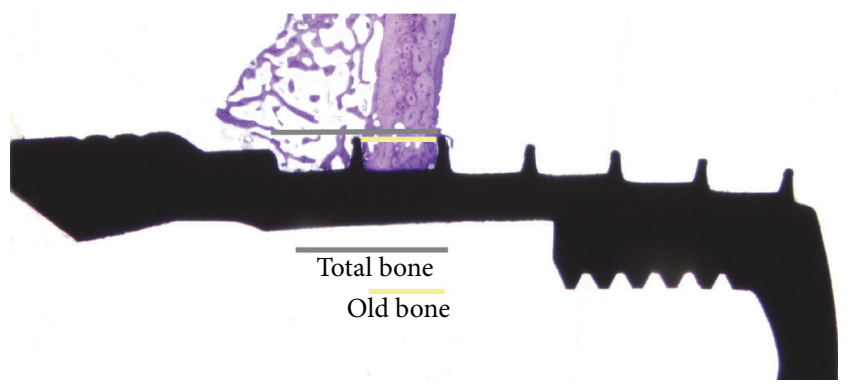

FIgURE 1: Method of measuring total bone and old bone for the new bone calculation. The new bone was calculated from the total amount of bone on each side of the implant on each histological sample minus the amount of old bone; then the percentage was calculated.

survey spectra were obtained using a PHI 5000C ESCA System (Perkin-Elmer Wellesley, USA). An $\alpha$ excitation source was used at $250 \mathrm{~W}$ with an operating angle of $45^{\circ}$.

2.3. Animals and Surgical Technique. 27 adult New Zeeland rabbits were divided into 3 groups (9 animals in each) with a healing time after implant insertion of 2, 4, and 9 weeks. Before surgery the animals were anaesthezised with an intramuscular injection of fentanyl $0.3 \mathrm{mg} / \mathrm{mL}$ and fluanisone $10 \mathrm{mg} / \mathrm{mL}$ (Hypnorm Vet, Janssen, Pharmaucetica, Beerse, Belgium) at a dose of $0.5 \mathrm{~mL}$ per $\mathrm{kg}$ body weight and an intraperitoneal injection of diazepam (Stesolid Novum, Alpharma, Denmark) at a dose of $2.5 \mathrm{mg}$ per animal. One $\mathrm{mL}$ of lidocaine (Xylocain, Astra, Sweden) was administered subcutaneously in the surgical site as analgesics and the operation was performed under aseptic conditions. One HA coated implant and one control implant was inserted into the left and right femur, respectively, therefore each animal served as its own control. The implant sites were prepared under irrigation with saline using increasing diameter of drills. Thereafter, the implant was inserted in the bone under saline irrigation. A single dose of prophylactic antibiotic sulfadoxin $200 \mathrm{mg} / \mathrm{mL}$ and trimethoprim $40 \mathrm{mg} / \mathrm{mL}$ (Borgal, Intervet, Boxmeer, Netherlands) at a dose of $0.5 \mathrm{~mL} / \mathrm{kg}$ and $0.5 \mathrm{~mL}$ buprenorphine $0.3 \mathrm{mg} / \mathrm{mL}$ (Temgesic, ScheringPlough, Belgium) were administrated immediately after the surgery. Right after surgery the rabbits were kept in separate cages to control the wound healing. They had free access to tap water and were fed with pellets and hay. After initial healing the rabbits were allowed to run freely in a specially designed room. The three groups of animals were sacrificed after 2, 4, and 9 weeks of healing with $10 \mathrm{~mL}$ overdose of pentobarbital $60 \mathrm{mg} / \mathrm{mL}$ (Pentobarbital-natrium, Apoteksbolaget, Sweden).

2.4. Removal Torque Analysis. A removal torque analysis was performed on each implant with an electrically controlled removal torque unit. The implants were subjected only to the necessary torque $(\mathrm{Ncm})$, to interrupt osseointegration, but were then not screwed out from the bone any further. This was done to enable histological evaluations of the bone complex.

2.5. Specimen Preparation and Histological Evaluation. After the torque analysis, each implant was removed in a block with the surrounding bone and fixed in $4 \%$ neutral buffered formaldehyde. Then the samples were dehydrated in alcohol solutions and embedded in light curing resin (Technovit 7200 VLC, Kultzer \& co, Germany). The cutting and grinding was performed as described by Donath [29]. The final sections were approximately $20 \mu \mathrm{m}$ thick and stained with toluidineblue. Histological evaluations were performed using a light microscope together with an image analysis software (Image analysis 2000, Sweden). The evaluations included measurements of the amount of new bone (NB) and bone area (BA) along the entire implant. The amount of NB was calculated from the total amount of bone minus the amount of old bone (Figure 1) with a $\times 4$ objective and $\mathrm{a} \times 10$ lens when needed for visualization. The bone area (BA) was evaluated in each thread on each implant and on the upper threadless part of the implant. The evaluations were made using a $\times 10$ objective and were presented as the mean value of all threads on the entire implant and as a mean of the three best threads on each side of the implant on histological sample. All measurements were made using $\mathrm{a} \times 10$ eye-pice and in a blinded manner.

2.6. Statistics. The statistical analysis was performed using SPSS (statistical package for the social studies). MannWhitney $U$-test was used and differences were considered significant at $P \leq 0.05$.

\section{Results}

Five animals experienced tibia fracture, two in each group with 2 and 9 weeks of healing time, and one in the group 


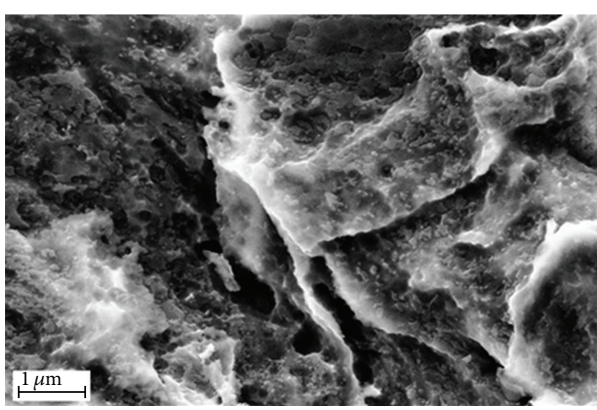

(a) Control

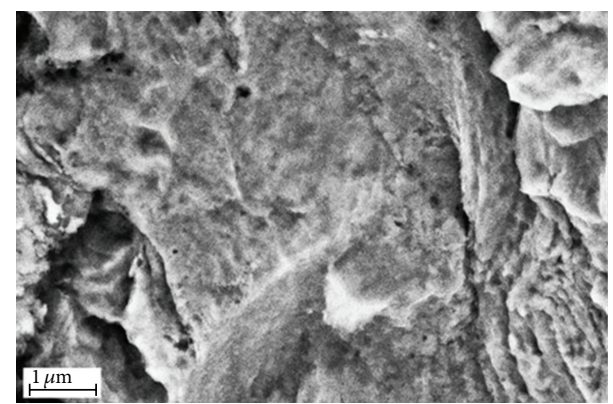

(b) Nano-HA

FIGURE 2: SEM images taken at $\times 40000$ magnification on (a) the control surface and (b) the nano-HA surface.

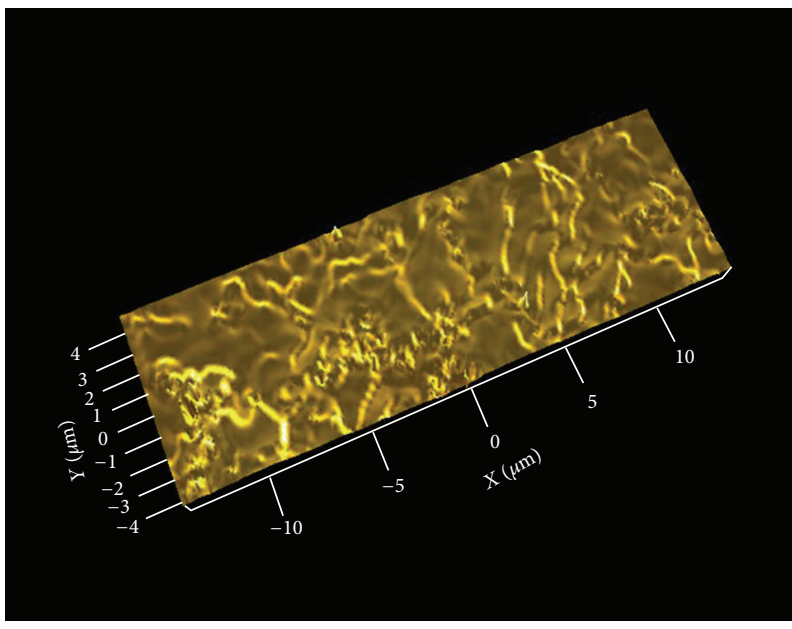

(a)

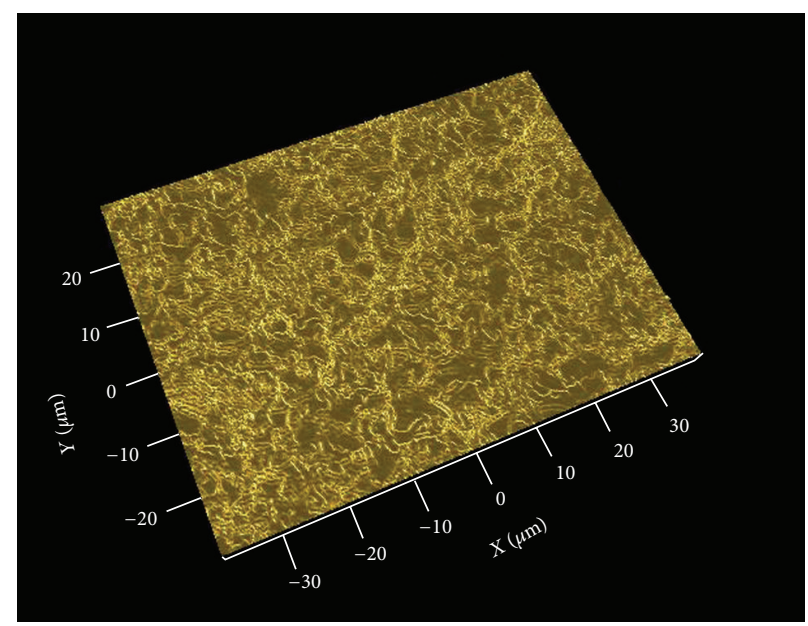

(b)

FIGURE 3: Images from the interferometer analysis of (a) the control titanium surface and (b) the test nano-HA surface.

with 4 weeks of healing time. These five rabbits had to be sacrificed in advance and were not included in the results. The postoperative period was uncomplicated for the rest of the rabbits. No signs of infection or inflammation were registered at the time of implant retrieval nor were other deviations from normal observed. All implants were stable at the time of retrieval.

\subsection{Implant Surface Characterization. SEM images of the} surfaces are shown in Figure 2.

Results from the interferometry analysis are presented in Table 1 and images of the surface topography are shown in Figure 3. Both implant types presented similar surface roughness on both micrometer and nanometer level. The mean $S_{a}$ value on the micrometer level was $1.08 \mu \mathrm{m}$ for the control implant and $0.93 \mu \mathrm{m}$ for the nano-HA coated one. There was no significant difference $(P>0.05)$ with respect to the evaluated surface parameters between test and control implants. Further, on the nanometer level, the mean $S_{a}$ value was $114 \mathrm{~nm}$ for the control and $119 \mathrm{~nm}$ for the nano-HA coated test implants, no significant difference $(P>0.05)$.

The XPS analysis showed presence of calcium and phosphorus on the surface of the coated test implants, while the controls had no such elements present (Figure 4). Furthermore, the XRD demonstrated the presence of crystalline HA (Figure 5).

3.2. Removal Torque Analysis. Results from the torque analysis showed no significant differences between the implant groups at any healing time $(P>0.05)$, see Figure 6. A slightly higher mean value for the nano-HA coated implants could be noted after 2 weeks of healing. No increase in torque value were seen after 4 weeks; however, after 9 weeks of healing the value increased for both implant types, but there were no significant differences between the implants.

3.3. Histological Results. Qualitative analysis of all the samples showed a normal inflammatory response in terms of few macrophages and neutrophils observed in the histological samples. After 4 weeks of healing there was a tendency for more new bone on the control implants compared with the coated nano-HA. However, there were no significant differences at any of the chosen healing times (Figure 7).

There was no difference between the implant groups when evaluating the bone area along the entire implant (Figure 8). However, when calculating the 3 best threads 


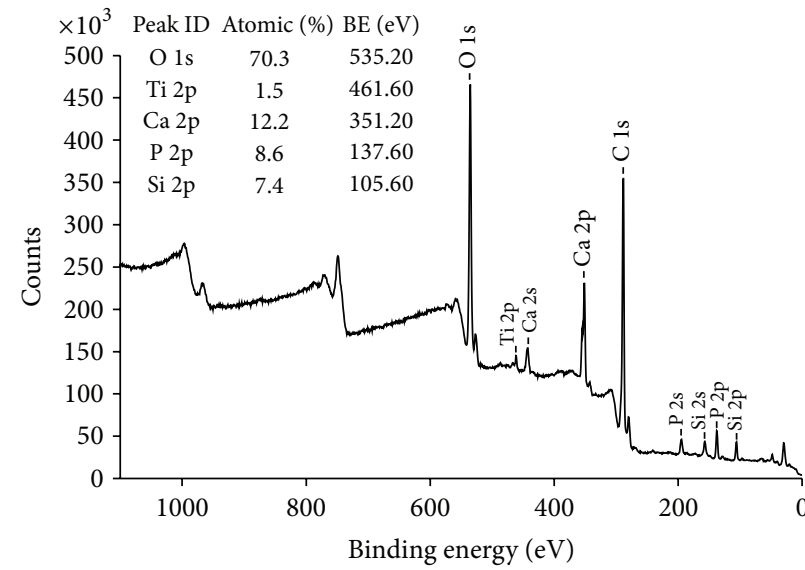

(a)

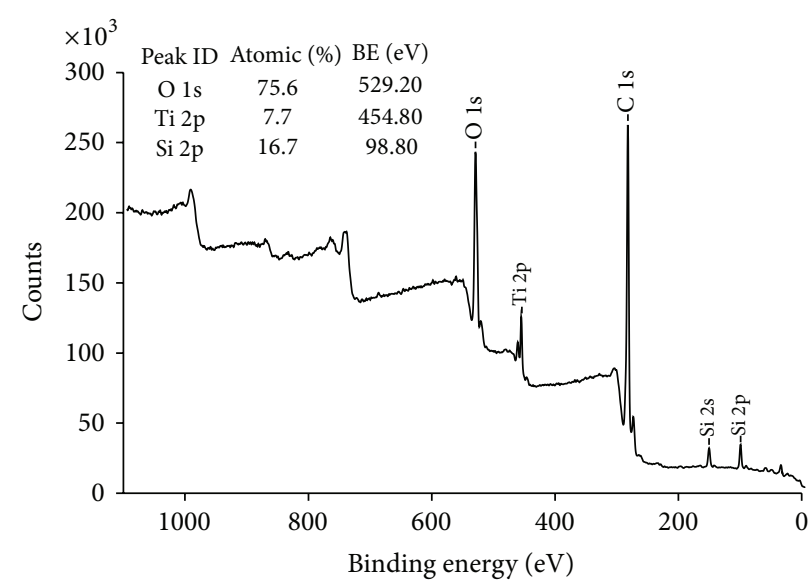

(b)

FIGURE 4: XPS survey spectra of (a) the test nano-HA surface and (b) the control titanium surface.

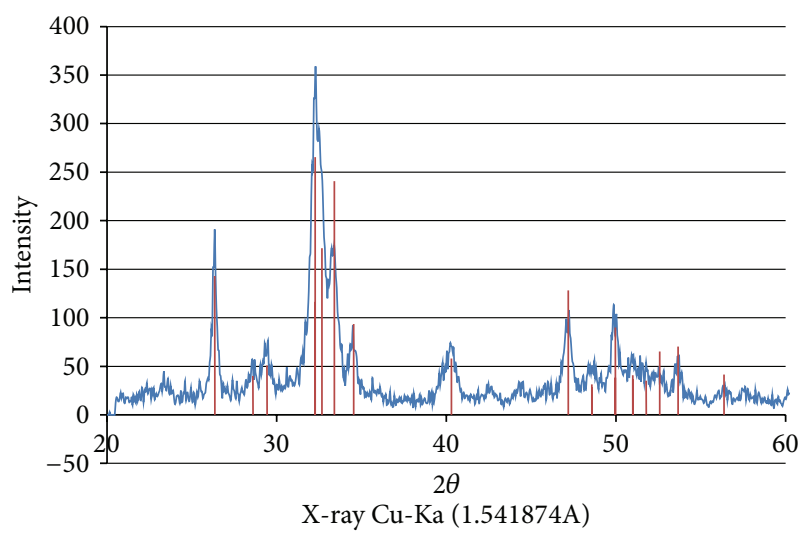

FIGURE 5: XRD demonstrating the presence of crystalline HA.

on each side of the samples, the control implant had a significantly $(P=0.025)$ higher value than the nano-HA after 9 weeks of healing. When evaluating the BA on the upper nonthreaded part of the implants there was also a significantly $(P=0.003)$ higher value for the control implant.

\section{Discussion}

An error search was made after the experimental part of the study was finished, since 5 rabbits unfortunately suffered from tibia fracture. The animal operations were made according to standard protocol and after well-documented procedures with no complications and by an experienced operator. After a close and strict error analysis, the authors could not find any explanation other than chance for these fractures.

The results from this study showed that both control and nano-Ha surfaces were biocompatible and osteoconductive. However, the submicron thick nano-HA coating did not improve the early bone healing compared to the control and the results support the following studies.

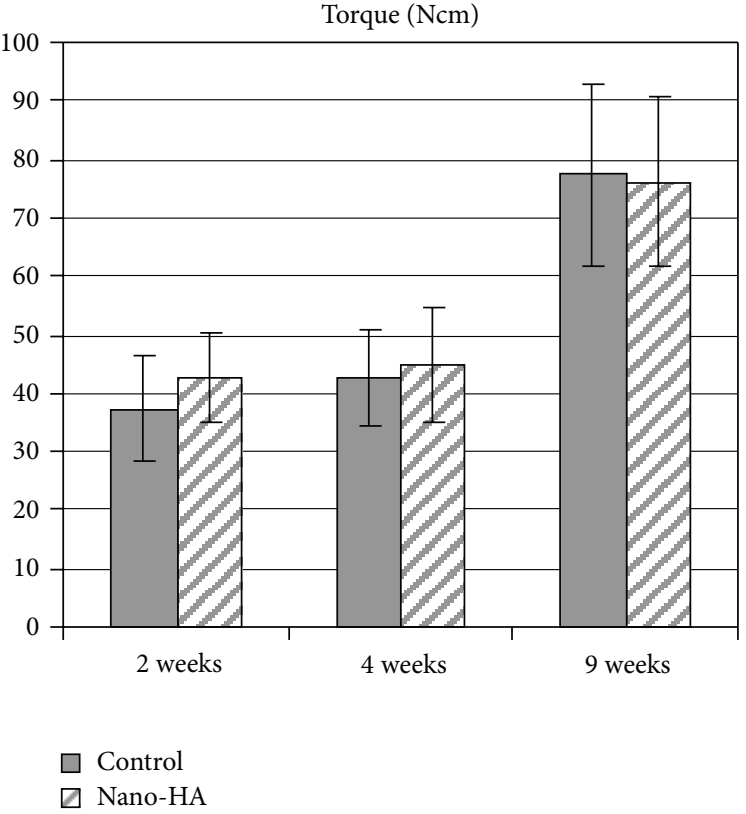

FIGURE 6: Removal torque results (mean value) after 2, 4, and 9 weeks of healing. The bar presents the standard deviation. Seven samples were evaluated in each group.

Coelho et al. (2009) showed that 20-50 nm thick CaP based coating on a blasted and etched cylindrical implants did not improve the biomechanical fixation or BIC after 2 and 4 weeks of healing in dog tibia [30]; an in vivo study in goat, on screw shaped grit-blasted, acid etched (GAE) and electrosprayed $\mathrm{CaP}$ nanoparticle-coated implants gave similar bone responses and torque values as to GAE alone [31]; Schliephake et al. (2009) did not find any significant difference in host response (foxhound) to dual acid etched (DAE) screw shaped implants coated with HA compared to DAE alone [32]. Further, Lee et al. (2009) concluded that screw shaped titanium or ceramic implants coated with HA 


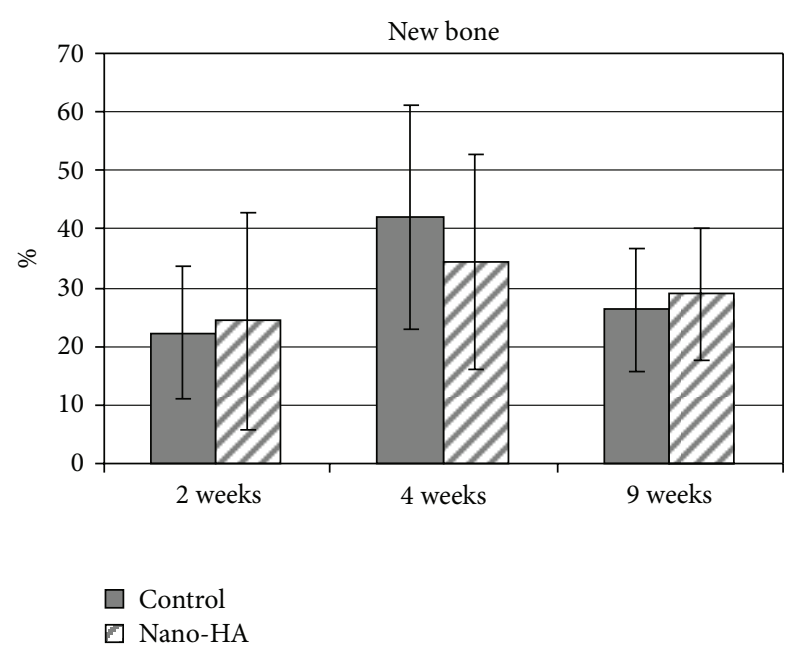

FIgURE 7: Amount of new bone after 2, 4, and 9 weeks of healing. The bar presents the standard deviation. Seven samples were evaluated in each group.

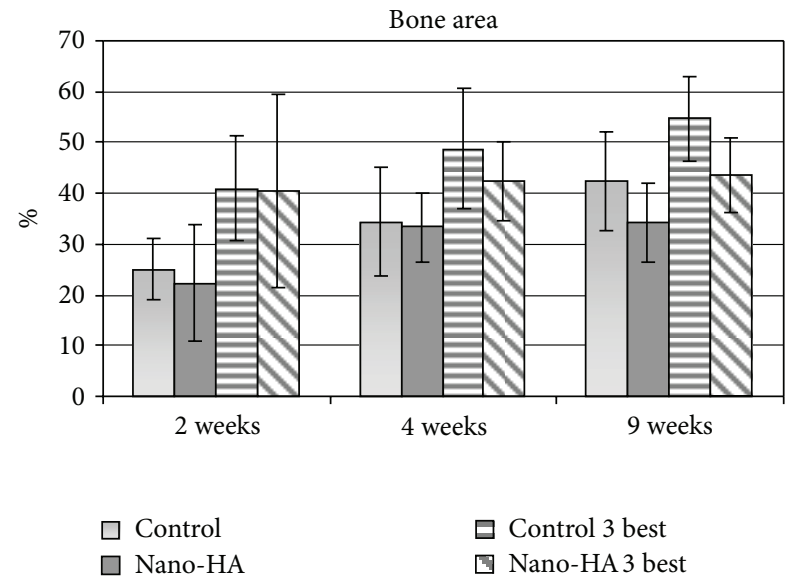

Figure 8: Bone area after 2, 4, and 9 weeks of healing. Presented in percentage as a mean of all threads and calculated for the three best threads on each side of each implant. The bar represents the standard deviation.

nanocrystals did not improve the early bone response in rabbit [33]; Svanborg et al. (2011) confirmed similar results [22]. However, there are other in vivo studies having shown positive effects on bone healing to various nanostructured $\mathrm{Ti}$ implants $[16,18,19,34]$.

As mentioned before, one theory behind this discrepancy in reported results has been that nanostructured Ti implants may be of benefit in bone with poor quality but of insignificant importance in the healing in sites that already provide excellent initial implant stability. However, the present study of implants placed in trabecular bone did not support this theory on trabecular bone influence on implant outcome. Several in vivo and some clinical studies have tried to clarify the importance of nanosized structures in early bone healing and osseointegration. Although the studies are performed in different animals, the size, shape, and chemical composition of the nanostructures are also often different and therefore the studies are very difficult to compare. The difference in results from previous studies might be explained by differences in nanotopography; however the possible effect of the surface chemical composition cannot be excluded. Hence, further studies are needed to be able to conclude if some type of nanostructure may influence the bone healing and also if they might be of significance in the treatment of patients.

\section{Conclusion}

According to the results from this present study, both control and nano-Ha surfaces were biocompatible and osteoconductive. A coating of hydroxyapatite nanocrystals deposited onto blasted and acid etched screw shaped titanium implants did not enhance bone healing after 2, 4, or 9 weeks compared to a blasted and etched control implants.

\section{Conflict of Interests}

The authors declare that there is no conflict of interests regarding the publication of this paper.

\section{Acknowledgments}

This study was supported by Wilhelm and Martina Lundgren Science Foundation, Hjalmar Svensson Foundation, Sigge Perssons \& Alice Nybergs Stiftelse (Gothenburg Dental Society), and the Swedish Dental Society, the Swedish Research Council, and Royal Society of Art Sciences in Göteborg. Petra Johansson and Ann Albrektsson are gratefully acknowledged for the preparation of the histological samples.

\section{References}

[1] P. Astrand, B. Engquist, S. Dahlgren, K. Gröndahl, E. Engquist, and H. Feldmann, "Astra Tech and Brånemark system implants: a 5-year prospective study of marginal bone reactions," Clinical Oral Implants Research, vol. 15, no. 4, pp. 413-420, 2004.

[2] N. J. Attard and G. A. Zarb, "Long-term treatment outcomes in edentulous patients with implant-fixed prostheses: the Toronto study," International Journal of Prosthodontics, vol. 17, no. 4, pp. 417-424, 2004.

[3] T. Jemt, "Single implants in the anterior maxilla after 15 years of follow-up: comparison with central implants in the edentulous maxilla," International Journal of Prosthodontics, vol. 21, no. 5, pp. 400-408, 2008.

[4] U. Lekholm, K. Gröndahl, and T. Jemt, "Outcome of oral implant treatment in partially edentulous jaws followed 20 years in clinical function," Clinical Implant Dentistry and Related Research, vol. 8, no. 4, pp. 178-186, 2006.

[5] T. Albrektsson, P. Branemark, H. Hansson, and J. Lindstrom, "Osseointegrated titanium implants. Requirements for ensuring a long-lasting, direct bone-to-implant anchorage in man," Acta Orthopaedica Scandinavica, vol. 52, no. 2, pp. 155-170, 1981.

[6] A. Wennerberg, On Surface Roughness and Implant Incorporation, Department of Biomaterials/Handicap Research, University of Gothenburg, Gothenburg, Sweden, 1996.

[7] P. T. de Oliveira and A. Nanci, "Nanotexturing of titaniumbased surfaces upregulates expression of bone sialoprotein and 
osteopontin by cultured osteogenic cells," Biomaterials, vol. 25, no. 3, pp. 403-413, 2004.

[8] P. T. de Oliveira, S. F. Zalzal, M. M. Beloti, A. L. Rosa, and A. Nanci, "Enhancement of in vitro osteogenesis on titanium by chemically produced nanotopography," Journal of Biomedical Materials Research A, vol. 80, no. 3, pp. 554-564, 2007.

[9] K. L. Elias, R. L. Price, and T. J. Webster, "Enhanced functions of osteoblasts on nanometer diameter carbon fibers," Biomaterials, vol. 23, no. 15, pp. 3279-3287, 2002.

[10] R. L. Price, M. C. Waid, K. M. Haberstroh, and T. J. Webster, "Selective bone cell adhesion on formulations containing carbon nanofibers," Biomaterials, vol. 24, no. 11, pp. 1877-1887, 2003.

[11] B. C. Ward and T. J. Webster, "The effect of nanotopography on calcium and phosphorus deposition on metallic materials in vitro," Biomaterials, vol. 27, no. 16, pp. 3064-3074, 2006.

[12] T. J. Webster and J. U. Ejiofor, "Increased osteoblast adhesion on nanophase metals: Ti, Ti6Al4V, and CoCrMo," Biomaterials, vol. 25, no. 19, pp. 4731-4739, 2004.

[13] T. J. Webster, C. Ergun, R. H. Doremus, R. W. Siegel, and R. Bizios, "Enhanced functions of osteoblasts on nanophase ceramics," Biomaterials, vol. 21, no. 17, pp. 1803-1810, 2000.

[14] A. Goransson, A. Arvidsson, F. Currie et al., "An in vitro comparison of possibly bioactive titanium implant surfaces," Journal of Biomedical Materials Research A, vol. 88, no. 4, pp. 1037-1047, 2009.

[15] M. Sato, A. Aslani, M. A. Sambito, N. M. Kalkhoran, E. B. Slamovich, and T. J. Webster, "Nanocrystalline hydroxyapatite/titania coatings on titanium improves osteoblast adhesion," Journal of Biomedical Materials Research A, vol. 84, no. 1, pp. 265-272, 2008.

[16] L. M. Bjursten, L. Rasmusson, S. Oh, G. C. Smith, K. S. Brammer, and S. Jin, "Titanium dioxide nanotubes enhance bone bonding in vivo," Journal of Biomedical Materials Research A, vol. 92, no. 3, pp. 1218-1224, 2010.

[17] L. Meirelles, A. Arvidsson, M. Andersson, P. Kjellin, T. Albrektsson, and A. Wennerberg, "Nano hydroxyapatite structures influence early bone formation," Journal of Biomedical Materials Research A, vol. 87, no. 2, pp. 299-307, 2008.

[18] V. C. Mendes, R. Moineddin, and J. E. Davies, "The effect of discrete calcium phosphate nanocrystals on bone-bonding to titanium surfaces," Biomaterials, vol. 28, no. 32, pp. 4748-4755, 2007.

[19] R. J. Goené, T. Testori, and P. Trisi, "Influence of a nanometerscale surface enhancement on de novo bone formation on titanium implants: a histomorphometric study in human maxillae," International Journal of Periodontics and Restorative Dentistry, vol. 27, no. 3, pp. 211-219, 2007.

[20] T. Albrektsson, "Hydroxyapatite-coated implants: a case against their use," Journal of Oral and Maxillofacial Surgery, vol. 56, no. 11, pp. 1312-1326, 1998.

[21] L. Le Guéhennec, A. Soueidan, P. Layrolle, and Y. Amouriq, "Surface treatments of titanium dental implants for rapid osseointegration," Dental Materials, vol. 23, no. 7, pp. 844-854, 2007.

[22] L. M. Svanborg, M. Hoffman, M. Andersson, F. Currie, P. Kjellin, and A. Wennerberg, "The effect of hydroxyapatite nanocrystals on early bone formation surrounding dental implants," International Journal of Oral and Maxillofacial Surgery, vol. 40, no. 3, pp. 308-315, 2011.
[23] M. M. Bornstein, B. Schmid, U. C. Belser, A. Lussi, and D. Buser, "Early loading of non-submerged titanium implants with a sandblasted and acid-etched surface: 5-year results of a prospective study in partially edentulous patients," Clinical Oral Implants Research, vol. 16, no. 6, pp. 631-638, 2005.

[24] P. Kjellin and M. Andersson, "Synthetic nano-sized crystalline calcium phosphate and method of production patent," SE0401524-4, 2006.

[25] A. Wennerberg and T. Albrektsson, "Suggested guidelines for the topographic evaluation of implant surfaces," International Journal of Oral and Maxillofacial Implants, vol. 15, no. 3, pp. 331344, 2000.

[26] L. M. Svanborg, M. Andersson, and A. Wennerberg, "Surface characterization of commercial oral implants on the nanometer level," Journal of Biomedical Materials Research B, vol. 92, no. 2, pp. 462-469, 2010.

[27] A. Arvidsson, B. A. Sater, and A. Wennerberg, "The role of functional parameters for topographical characterization of bone-anchored implants," Clinical Implant Dentistry and Related Research, vol. 8, no. 2, pp. 70-76, 2006.

[28] K. J. Stout, P. J. Sullivan, W. P. Dong et al., The Development of Methods For Characterisation of Roughness in Three Dimensions, EUR, 15178 EN of Commission of the European Communities, University of Birmingham, Birmingham, UK, 1993.

[29] K. Donath, Preparation of Histologic Sections by the CuttingGrinding Technique for Hard Tissue and Other Material Not Suitable to Be Sectioned by Routine Methods, EXAKT-KulzerPublication, Norderstedt, Germany, 1987.

[30] P. G. Coelho, G. Cardaropoli, M. Suzuki, and J. E. Lemons, "Early healing of nanothickness bioceramic coatings on dental implants. An experimental study in dogs," Journal of Biomedical Materials Research B, vol. 88, no. 2, pp. 387-393, 2009.

[31] C. Schouten, G. J. Meijer, J. J. J. P. van den Beucken et al., “In vivo bone response and mechanical evaluation of electrosprayed $\mathrm{CaP}$ nanoparticle coatings using the iliac crest of goats as an implantation model," Acta Biomaterialia, vol. 6, no. 6, pp. 22272236, 2010

[32] H. Schliephake, A. Aref, D. Scharnweber, S. Rößler, and A. Sewing, "Effect of modifications of dual acid-etched implant surfaces on periimplant bone formation-part II: calcium phosphate coatings," Clinical Oral Implants Research, vol. 20, no. 1, pp. 38-44, 2009.

[33] J. Lee, J. H. Sieweke, N. A. Rodriguez et al., "Evaluation of nanotechnology-modified zirconia oral implants: a study in rabbits," Journal of Clinical Periodontology, vol. 36, no. 7, pp. 610-617, 2009.

[34] G. Orsini, M. Piattelli, A. Scarano et al., "Randomized, controlled histologic and histomorphometric evaluation of implants with nanometer-scale calcium phosphate added to the dual acid-etched surface in the human posterior maxilla," Journal of Periodontology, vol. 78, no. 2, pp. 209-218, 2007. 


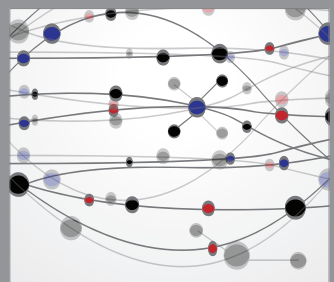

The Scientific World Journal
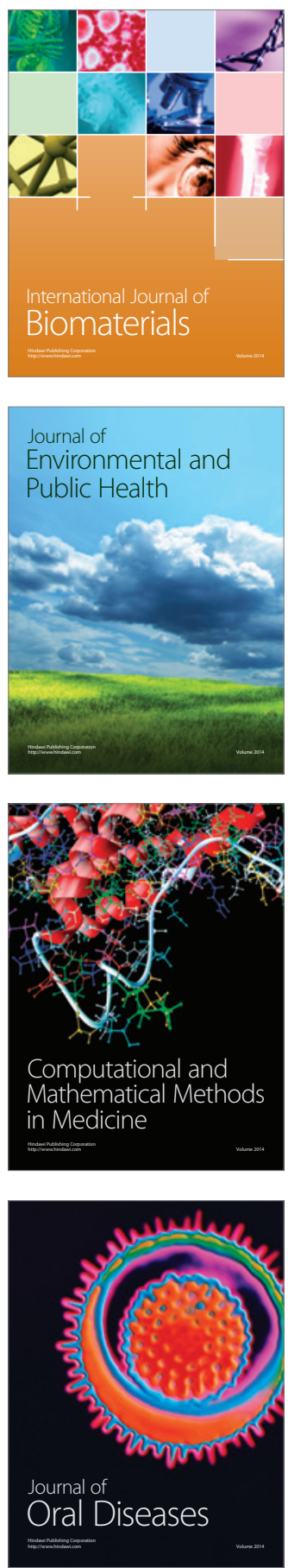
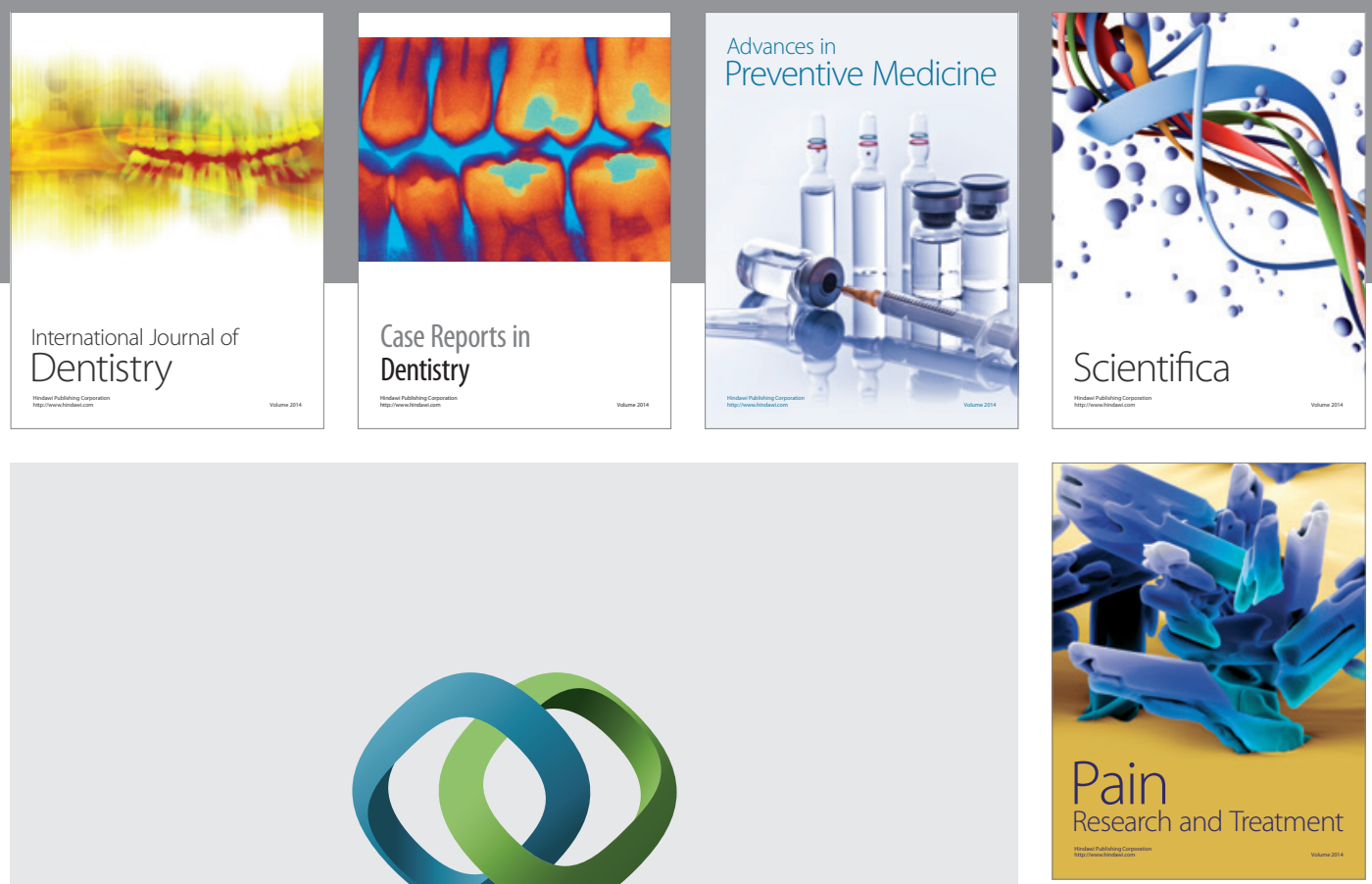

\section{Hindawi}

Submit your manuscripts at

http://www.hindawi.com
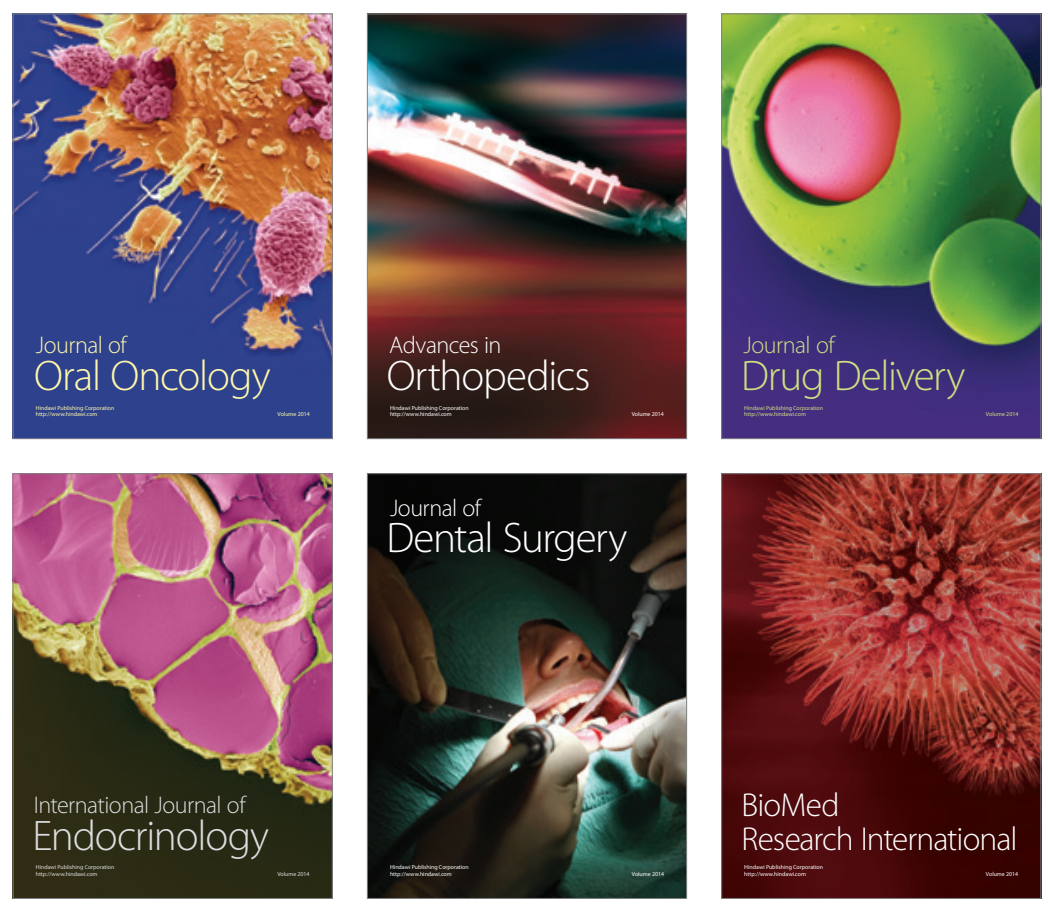

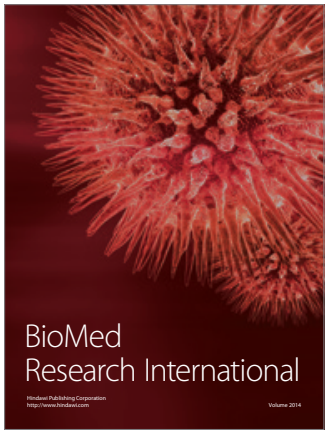

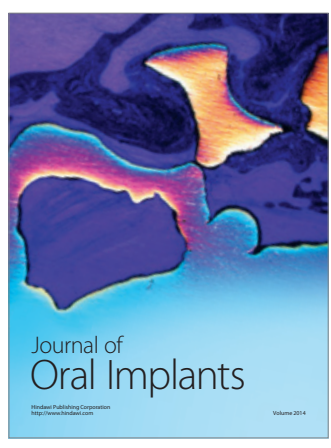
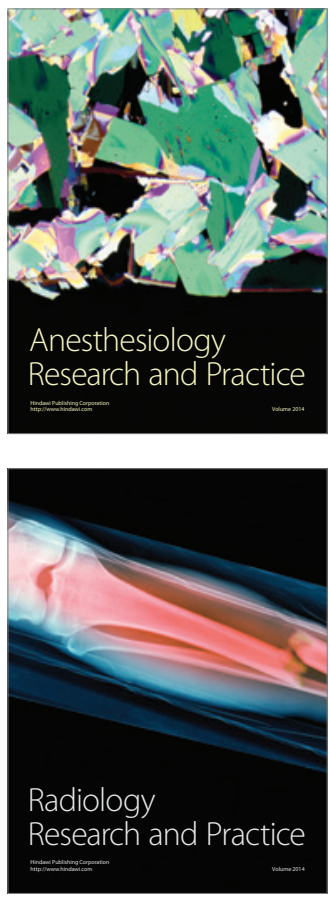